\title{
Waste seeds of Mangifera indica, Artocarpus heterophyllus, and Schizizium commune as biochar for heavy metal removal from simulated wastewater
}

\author{
Deen Dayal Giri ${ }^{4}$ Jay Mant $\mathrm{Jha}^{5} \cdot$ Neha Srivastava $^{6} \cdot$ Maulin Shah $^{7} \cdot$ Atiah H. Almalki $^{1,2} \cdot$ Mustfa F Alkhanani $^{8}$. \\ Dan Bahadur Pal ${ }^{3}$
}

Received: 16 September 2021 / Revised: 31 October 2021 / Accepted: 1 November 2021

(c) The Author(s), under exclusive licence to Springer-Verlag GmbH Germany, part of Springer Nature 2021

\begin{abstract}
The threat of arsenic contamination in water is a challenging issue worldwide. Millions of people utilize untreated groundwater having high levels of arsenic in developing countries. Design Expert 6.0.8 has been used to design experiments and carried out statistical analysis for optimization of different parameters. It is of prime importance to develop cheap environment friendly bio-sorbent for protecting health of the poor from ill effects of arsenic. In the present investigation, we prepared bio-sorbent from the solid waste seed biomass of Mangifera indica (M), Artocarpus heterophyllus (JF), and Schizizium commune (JP). The characterization of bio-sorbents has been done by using different techniques namely FTIR and XRD. Arsenic concentration was estimated using ICP and adsorption parameters optimized for $\mathrm{pH}$, adsorbent dose, and initial arsenic concentration. At pH 8.4, kinetics study of arsenic removal was M (94\%), JF (93\%), and JP (92\%) for initial concentration of $2.5 \mathrm{ppm}$. The adsorption kinetics was well explained by Freundlich model and pseudo-second reaction order.
\end{abstract}

Keywords Arsenic removal $\cdot$ Bio-adsorbent $\cdot$ Schiziziumcommun $\cdot$ Mangiferaindica $\cdot$ Biochar

Dan Bahadur Pal

danbahadur.chem@gmail.com

Atiah H. Almalki

ahalmalki@tu.edu.sa

Mustfa F Alkhanani

mkhanani@mcst.edu.sa

1 Department of Pharmaceutical Chemistry, College of Pharmacy, Taif University, P.O. Box 11099 Taif- 21944, Saudi Arabia

2 Addiction and Neuroscience Research Unit, College of Pharmacy, Taif University, Al-Hawiah, Taif-21944, Saudi Arabia

3 Department of Chemical Engineering, Birla Institute of Technology, Mesra Ranchi-835215, Jharkhand, India

4 Department of Botany, Maharaj Singh College, Saharanpur-247001, Uttar Pradesh, India

5 Department of Chemical Engineering, Maulana Azad National Institute of Technology, Bhopal- 462003 Madhya Pradesh, India

6 Department of Chemical Engineering and Technology, Indian Institute of Technology (BHU), Varanasi 221005, India

7 Environmental Technology Limited, Ankeleshwar, Gujrat, India

8 College of Applied Sciences, AlMaarefa University, Riyadh, Saudi Arabia

\section{Introduction}

Presence of arsenic in the form of trivalent arsenite (As III) and pentavalent arsenate (As V) in the terrestrial and aquatic habitats is threatening human health seriously. As per World Health organization, arsenic is group one human carcinogen [1]. In surface water, the forms of arsenic are transformed from their inorganic to partially organic behavior due to biological activity. Arsenic is naturally present in the water of across the globe including the USA, Mexico, Argentina, India, and Bangladesh [2]. In addition to natural presence of it, some anthropogenic activities also enhance its percentage in soil and water. Apart from natural source of arsenic, many industries like mining, cement production, and fossil fuel burning are producing it. The use of arsenic based herbicides and pesticides pollute agriculture field [3, 4]. The arsenic present in agriculture field on the plant surface may reach to the human body directly with improperly washed food surface. Alternatively, it may enter in aquatic water bodies with runoff or percolate to groundwater and enters in the human body with drinking water and cause ill effects to human in long term [5]. However, most of the environmental arsenic problems are due to natural sources. Predominant forms of arsenic in the toxic condition of running water and pond 
is pentavalent arsenic acid and oxyanionic forms, whereas, in the anoxic or moderately reducing conditions of groundwater it exists in more stable trivalent arsenite (As III). Predominant form of arsenic is determined the $\mathrm{pH}$ value. In the natural water bodies of $\mathrm{pH}$ ranging from 5 to 8 , the pentavalent form is about five times compared to trivalent form [6]. The groundwater arsenic concentration may be high up to the level of $3500 \mathrm{ppm}$, and its toxicity affected population is more than 200 million globally [7]. The concentration of arsenic has been frequently reported high in different water bodies across the world. Considering the toxic and carcinogenic nature, a 10-ppm concentration of arsenic in drinking is the maximum permissible limit [27].

Efforts have been made to remove arsenic from polluted water bodies employing techniques like coagulation, flocculation, membrane filtration, reverses osmosis, precipitation, bio-remediation, and adsorption. These water treatment technologies are continuously being updated to achieve the aim of easy, efficient, and cost-effective treatment of arsenic polluted water [28]. Nanomaterials have been synthesized from iron oxides and copper nano-flakes activated carbons as low cast alternatives [8]. The nano-materials with unique porous structure and high chemical and mechanical resistance are useful, and they are efficiently employed for the purpose [9-11]. The powdered nano-adsorbent adsorbs metal from wastewater and leaving clean water on the top of the vessel.

Variety of materials has been tested as adsorbent and adsorption behavior in the including stones, shells, and even sewage products, in recent past. However, the use of sewage product could give undesirable effects on the human body due to relatively less knowledge about the microorganisms or their enzymes present $[12,13]$. To reduce the adsorbents cost significantly wastes from the food industry and agriculture has been utilized, and these materials are generally described as bioadsorbent. Wastes of agriculture and food industry are potential bio-sorbent for arsenic removal from water. Bio-sorbents have also been prepared from the seeds of the plant and shown to be appropriate raw materials for bio-sorbents [14], [29]. Biochemically, bio-sorbents are composed of carbohydrate, lipid/fat, proteins, lignin, cellulose, and hemicelluloses materials in varying proportion depending upon the source plant. These compounds contain functional groups like hydroxyl, carboxyl, amide, amine, and carbamide that are able to facilitate complex formation and removal of arsenic from the aqueous solution [15].

Considering the need of cheap, efficient, eco-friendly, and potentially harmless bio-adsorbent, in the present investigation, we prepared easily available seed kernels of Mangifera indica (Mango), Artocarpus heterophyllus (Jack fruit, JF), and Schizizium commune (Java Plum, JP) for synthesizing bio-sorbents. In this current COVID 19 pandemic situation, the demand of fresh water increases tremendously. Most of the population in developing countries are depends of groundwater for their need. In the condition of increasing demand more hand pumps and bore wells are required in various regions so the chances of exposure of arsenic contaminated water increases continuously.

The aim of the current investigation was achieved for an efficient arsenic removal technique by using low-cost biomass adsorbent. The home-made adsorbent has been prepared and characterized using various techniques like FTIR and XRD. The experiments were performed for the duration of $120 \mathrm{~min}$ and sample was collected at a 10-min interval to check the kinetics. The experiments were performed by changing $\mathrm{pH}$, amount dose, and initial arsenic composition. The arsenic adsorption data of selected bio-adsorbents was well supported by spectroscopic data, adsorption isotherms, and kinetic models.

\section{Materials and method}

\subsection{Experimental procedure}

Batch adsorption experiment performed as explained elsewhere [8]. In brief, a experiment is performed in a 50-ml beaker containing arsenic solution and adsorbent continuously stirred by a magnetic stirrer with minimum of $5 \mathrm{rpm}$. Different aqueous arsenic concentration $(0.8,1,1.5,2$, and $2.5 \mathrm{ppm})$ were exposed separately to various doses $(20,40$, 60,80 , and $100 \mathrm{mg}$ ) of adsorbent at a pH (5 to 11) for optimizing the adsorption experiment. The experiments performed for $2 \mathrm{~h}$ and samples were withdrawn at the regular interval of $10 \mathrm{~min}$ and filtered with a $0.45 \mu$-filter before analysis for residual arsenic concentration in the solution using ICP.

The equilibrium test was performed for understanding arsenic sorption on bio-sorbent. Dry adsorbent $(0.5 \mathrm{~g} / \mathrm{L})$ was added in the flasks containing a $50 \mathrm{ml}$ arsenic solution $(\mathrm{pH}=7)$. The initial arsenic concentration of solution tested for adsorption range from 5 to $300 \mathrm{mg} / \mathrm{L}$. Arsenic solutions with bio-sorbents were stirred for $24 \mathrm{~h}$ and then bio-sorbents were filtered with $0.45 \mu$ filters. The equilibrium arsenic concentration, $\mathrm{Ce}(\mathrm{mg} / \mathrm{L})$, was determined by analyzing the filtrate by ICP. The sorption capacity $\left(\mathrm{mg} . \mathrm{g}^{-1}\right)$ of bio-sorbent at equilibrium is obtained using Equation given below:

$q_{e}=\frac{\left(C_{0-} C_{e}\right) V}{m}$

\subsection{Plants used for bio-sorbent}

All the angiospermic plants used in the present study are deciduous perennial trees. They are distributed across the India in different climatic zones. The Mangifera indica $\mathrm{L}$. is a very well-known economic fruit plant belonging to family Anacardiaceae; their fruits are irregularly egg-shaped. Syzygium cumini commonly called Jamun belongs to the family Myrtaceae. The plant has been well documented for its antidiabetic 
and hypoglycemic effects in its seed, fruit, and bark. Artocarpus heterophyllus is an evergreen tree of about 10-20 m that belongs to family Moraceae. The fruit contains 100-300 seeds $(10-12 \times 8-10 \mathrm{~mm})$, about $15-18 \%$ of the fruit weight. The seeds are good source of starch and protein. The seed starch has high tolerance for thermal and mechanical shear.

\subsection{Preparation of bio-sorbent}

Seeds of different fruits like mango, jackfruit, and jamun have been collected from campus of BIT Mesra, Ranchi and washed for removing adhered dust particles. The washed seeds were dried in the oven at $60{ }^{\circ} \mathrm{C}$ for $48 \mathrm{~h}$, and then it is crushed for making powder form. The powder was sieved and coarse particle obtained were milled again for preparing the homogeneous powder for various characterization and calcinations at $300{ }^{\circ} \mathrm{C}$ for $3 \mathrm{~h}$. The schematic diagram for preparation of bio-adsorbent has been shown in Fig. 1.

\subsection{Characterization of bio-adsorbent}

Field emission scanning electron microscopy-energy dispersive X-ray spectroscopy was recorded on Sigma-300 with EDX (Ametek). Fourier transform infrared spectrum of the prepared bio-adsorbent using Shimadzu (Corporation, Japan; IR-Prestige 21). For phase identification, X-ray diffraction (XRD) pattern was recorded using a Rigaku, Smart Lab $9 \mathrm{~kW}$ diffractometer (Japan). The elemental analysis is by ICP-OES in Perkin Elmer, Optical 2100DV ICP-OES (USA).

\subsection{Experimental design}

Design Expert 6.0.8 has been used to design the experiments for varying different parameters. The experimental planning has been done using Box-Behnken design within RSM to

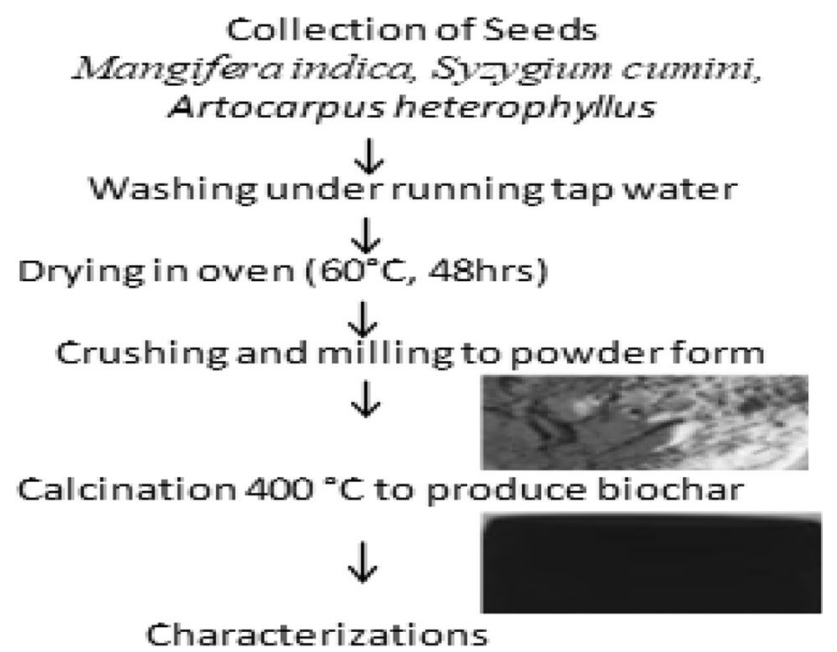

Fig. 1 Flow chart for preparation of bio-adsorbent optimize the parameters in order to maximize the \% removal of heavy metal present in water. Within this methodology, a 3 -factor, 3 levels Box-Behnken design have been useful to study the collective outcome of three constraint $\mathrm{pH}$, adsorbent doses, and concentration of heavy metal on the \% removal. The diversity of the different parameters has been given in Table 1 .

As per the experimental planning given by DOE, 17 experiments have been conducted and result has been fed to DOE for further analysis. The outcome of the statistical analysis is a fitted second-order polynomial in the form given below.

$Y=C_{0}+\sum C_{i} X_{i}+\sum C_{i i} X_{i i}^{2}+\sum C_{i j} X_{i} X_{j}+\epsilon$,

where $Y$ is the forecast yield, $C_{0}$ is constant and $C_{i}, C_{i i}$, and $C_{i j}$ are the linear constant, quadratic constant, and the cross-product constant, respectively.

\section{Result and discussion}

\subsection{FTIR analysis}

By using FTIR spectral analysis, the important functional groups on the surface of bio-adsorbent were analyzed and shown in Fig. 2. By observing the figure, it can be observed that, at wavenumber $3279 \mathrm{~cm}^{-1}$, the incorporation peak is linked with a hydroxyl group stretching vibration, and on other hand, wavenumbers around $2927 \mathrm{~cm}^{-1}$ and $2364 \mathrm{~cm}^{-1}$ observed for $\mathrm{C}-\mathrm{H}$ aliphatic stretching vibration [14]. It is also observed that the carboxyl double bond the peak seen at $1643 \mathrm{~cm}^{-1}$. Kim et al. 2015 has observed that the carboxyl group plays a vital role for cations metal absorption. The wave-number $1007 \mathrm{~cm}^{-1}$ was observed for the hydroxyl group and the peak at $929 \mathrm{~cm}^{-1}$ shows the carbon-carbon associates in the bio-carbon. The existence of polar groups on the bioadsorbent plane is possible to supply the significant cation substitute ability to the absorbent [34].

\subsection{XRD analysis}

The X-ray diffraction patterns of different waste seeds biochar powder were shown in Fig. 3. As seen in the figure, the crystalline phase availability was very small in the M, JF, and JP calcined at $400{ }^{\circ} \mathrm{C}$ for $3 \mathrm{~h}$, and the large amount of amorphous

Table 1 Optimization variables with independent test

\begin{tabular}{lllll}
\hline Variables & Unit & \multicolumn{2}{l}{ Range and level } \\
\cline { 3 - 5 } & & Low & Medium & High \\
\hline $\mathrm{pH}$ & - & 5 & 7 & 9 \\
Adsorbent doses & $p p m$ & 40 & 60 & 80 \\
Concentration & ppm & 1 & 1.5 & 2 \\
\hline
\end{tabular}




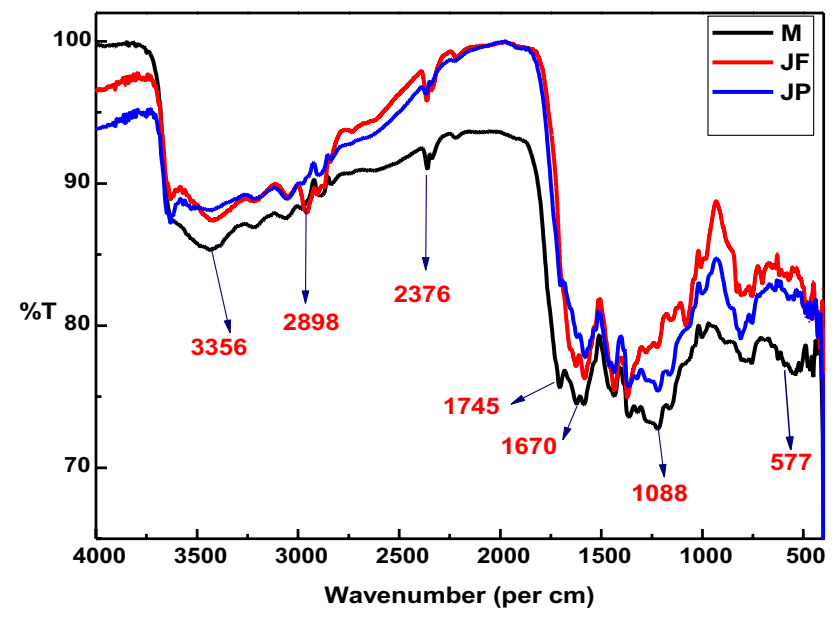

Fig. 2 FTIR spectra of bio-sorbent material of Mangifera indica (MF), Artocarpus heterophyllus (JF), and Schizizium commune (JP) calcined at $400{ }^{\circ} \mathrm{C}$ for $3 \mathrm{~h}$

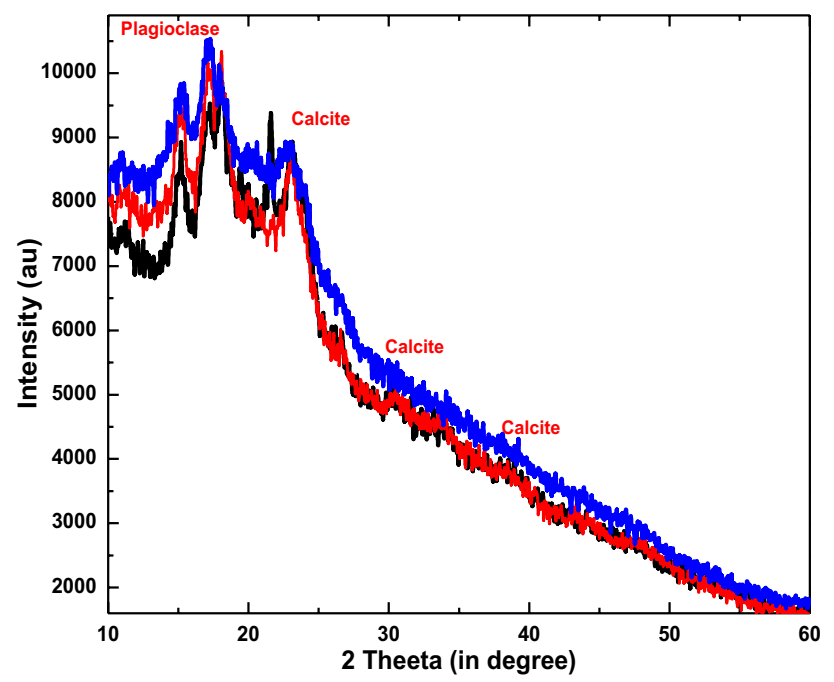

Fig. 3 XRD spectra of bio-sorbent material of Mangifera indica (MF), Artocarpus heterophyllus (JF), and Schizizium commune (JP)

part. The crystalline parts of maximum calcite $(\mathrm{Cc})$ and plagioclase $(\mathrm{Pl})$ and also different compositions of carbon are in biochar. The various peaks present in biochar at theta angles such as $14.89,17.45,22.87$, and 37.97 [32]. The similar peaks found in biochars corresponded to calcite $(\mathrm{Cc})$ and plagioclase (Pl) due to the alkaline oxyhydroxides formed during biochar fabrication [10], [30].

\subsection{Kinetics study and equilibrium isotherm}

In this research work, the arsenic removal percentage is observed, and by using three bio-adsorbents (MF, JF, and JP), it is primarily reported as shown in Fig. 4. The figure shows that the amount of adsorption of arsenic is varied with time of reaction proceeded. The arsenic adsorption gets slow down after half an hour about $70 \%$, and after that enhanced the removal of arsenic using biochar of $\mathrm{M}$ (93.64\%), JF (92.8\%), and JP (92.64\%). All these three adsorbents tested, i.e., MF, JF, and JP in 90 min duration, and at room temperature keeping $\mathrm{pH} 8.4$, the experiment performed for a 120-min duration. To predict the adsorption kinetics, the four models have been applied using all three catalysts [19].

As shown in Table 2, the different models of describes the experimental data satisfied with high coefficients with comparison of recent studies. In case of the entire three bio-sorbents, Freundlich model $\left(R^{2}=0.99 \mathrm{MF}, R^{2}=0.98\right.$ $\mathrm{JF}, R^{2}=0.98 \mathrm{JP}$ ) and pseudo-first-order reaction kinetic $\left(R^{2}=0.98 \mathrm{MF}, R^{2}=0.97 \mathrm{JF}, R^{2}=0.97 \mathrm{JP}\right)$ well explained the adsorption and reaction kinetics.

Regression coefficients shown in a comparative of different kinetic models are presented in Table 3. It can be found from the table that the current and earlier study showed with regression coefficients and constants such as date seed [10], starch maghemite [20], Delonix seed biochar [10] amaltash seed biochar [9], and seed [9].

To observe the premium adsorption isotherm, the bioadsorbents MF, JP, and JF were selected for adsorption and investigational information. The mechanism of adsorption isotherm was explained by using Langmuir, Freundlich, and Tempkin model isotherms which has mentioned as above in equation (See supplementary materials). The value of $R^{2}$ is the indicative of the most excellent possible isotherm [21]. Table 3 shows the outcome of isotherm studies the entire three models, and graphically it was presented in Fig. 4 (B, C, D). From Table 3, it can be seen that the value of $R^{2}$ in Freundlich isotherm model is 0.98 for MF, 0.98 for JF, and 0.98 for JP seed catalyst. Other studies also show the similar results of the various coefficients [22].

From the Table 3 summary of equilibrium constraint of various models and their regression constants, the current investigation gives better results showed than recent researchers such as maghemite [20], date seed [10], and Delonix seed biochar [10].

\subsection{Effects of various parameters on arsenic removal}

The obtained results in terms of $\%$ removal for all the individual experiments are analyzed in the Design of Expert software. The enhanced investigation also performed for capitalization on the percentage removal at optimal values of procedure constraint and is present in the following subsections. The progression constraints ( $\mathrm{pH}$, bio-adsorbent doses, and concentration of arsenic metal) have been various in three different stages for 
Fig. 4 Effect of time on the $\%$ arsenic removal (A) and adsorption model $(\mathbf{B}, \mathbf{C}, \mathbf{D})$ for arsenic removal from aqueous solution by the seed bio-sorbent of Mangifera indica (MF), Artocarpus heterophyllus $(\mathrm{JF})$, and Schizizium commune (JP)
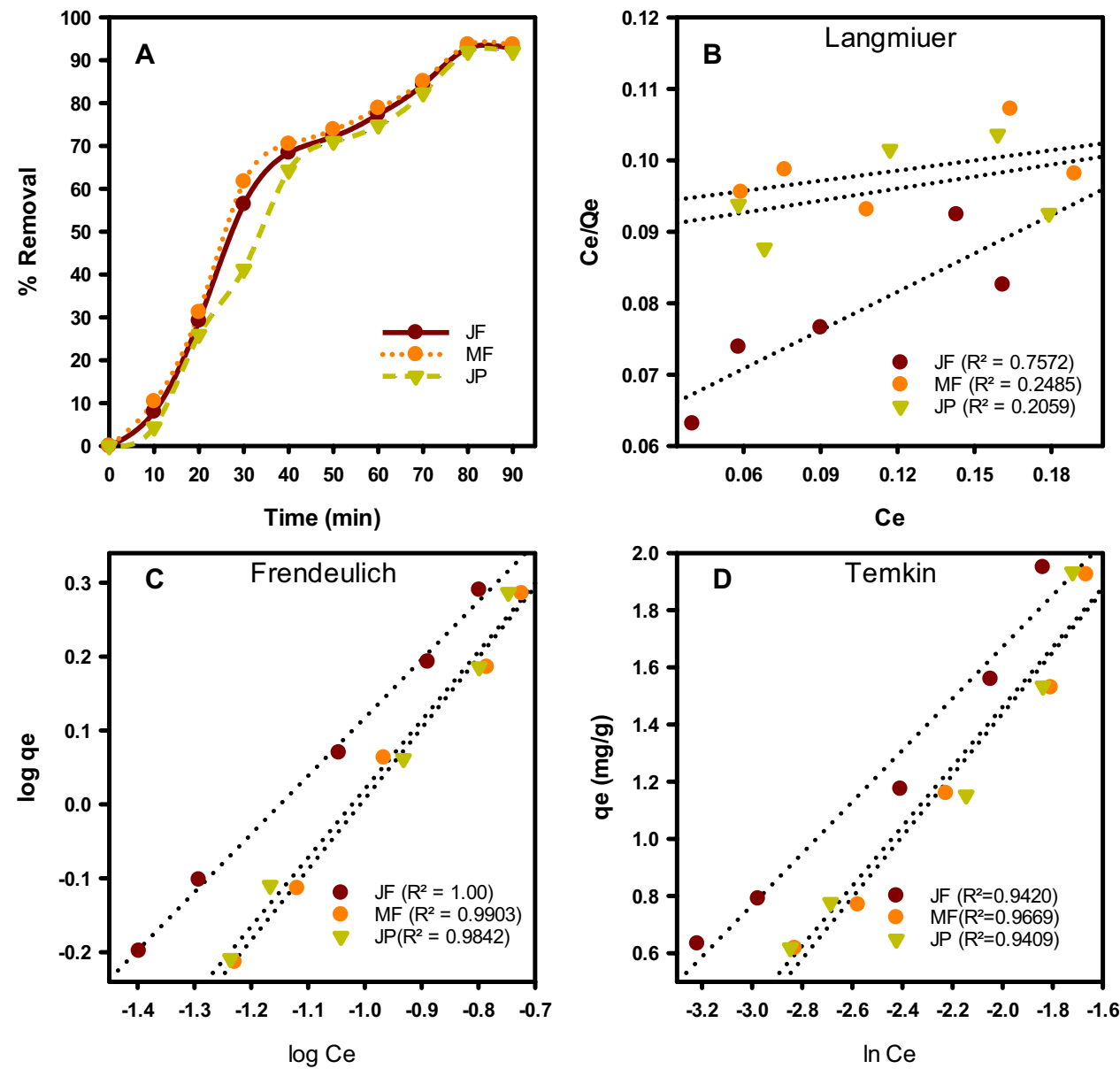

Table 2 Summary of kinetic of arsenic adsorption on seeds biochar of Mangifera indica (M), Artocarpus heterophyllus (JF), and Schizizium commune (JP)

\begin{tabular}{|c|c|c|c|c|c|c|c|}
\hline Kinetic model & Parameters & $\begin{array}{l}M \text { (present } \\
\text { study) }\end{array}$ & $\begin{array}{l}\text { JF (present } \\
\text { study) }\end{array}$ & $\begin{array}{l}\text { JP } \\
\text { (present study) }\end{array}$ & $\begin{array}{l}\text { Starch magh- } \\
\text { emite (Siddiqui } \\
\text { et al. 2020) }\end{array}$ & $\begin{array}{l}\text { Delonix seed } \\
\text { biochar [10] }\end{array}$ & $\begin{array}{l}\text { Seed } \\
{[31]}\end{array}$ \\
\hline \multirow{3}{*}{$\begin{array}{l}\text { Pseudo-first } \\
\text { order }\end{array}$} & $k_{1}\left(\min ^{-1}\right)$ & 0.083 & 0.076 & 0.074 & 0.06 & 0.101 & 0.038 \\
\hline & $q_{e}(\mathrm{mg} / \mathrm{g})$ & 5.87 & 6.52 & 7.33 & 2.76 & 4.79 & 0.0033 \\
\hline & $R^{2}$ & 0.985 & 0.979 & 0.972 & 0.60 & 0.921 & 0.9228 \\
\hline \multirow{3}{*}{$\begin{array}{l}\text { Pseudo-second } \\
\text { order }\end{array}$} & $k_{2}(\mathrm{~g} / \mathrm{mg} \cdot \min )$ & 0.0082 & 0.0036 & 0.00045 & 9.16 & 0.212 & 0.087 \\
\hline & $q_{e}(\mathrm{mg} / \mathrm{g})$ & 2.81 & 3.51 & 7.75 & 1.03 & 1.675 & 0.753 \\
\hline & $R^{2}$ & 0.741 & 0.442 & 0.042 & 0.99 & 0.96 & 0.9837 \\
\hline \multirow[t]{3}{*}{$\begin{array}{l}\text { Intra-particle } \\
\text { model }\end{array}$} & $\begin{array}{l}K_{\mathrm{ipd}} \\
\quad\left(\mathrm{mgg}^{-1} \min ^{-1 / 2}\right)\end{array}$ & 0.229 & 0.21 & 0.217 & 0.03 & 0.274 & 2.01536 \\
\hline & $\mathrm{C}\left(\mathrm{mg} \mathrm{g}^{-1}\right)$ & 0.148 & 0.115 & 0.216 & 0.62 & 0.698 & 0.17576 \\
\hline & $R^{2}$ & 0.95 & 0.926 & 0.927 & 0.90 & 0.78 & 0.6254 \\
\hline \multirow[t]{3}{*}{ Elovich model } & $\beta\left(\mathrm{g} \mathrm{mg}^{-1}\right)$ & 47.62 & 1.314 & 1.13 & 9.93 & 0.3775 & 6.313 \\
\hline & $\alpha\left(\operatorname{mggmin}^{-1}\right)$ & 1.94 & 0.030 & 0.0094 & 9.76 & 1.4257 & $5.44 \times 10^{-6}$ \\
\hline & $R^{2}$ & 0.886 & 0.966 & 0.984 & 0.81 & 0.93 & 0.6202 \\
\hline
\end{tabular}

design optimizes study, and 17 different experiment runs have been investigated. For each experiment, the percentage removal has been estimated and fed to the DOE software for additional analysis. DOE guesses the model quadratic equation which communicates the independent variables $(\mathrm{pH}$, bio-adsorbent doses, and concentration 
Table 3 Summary of adsorption isotherm of Arsenic on Mangifera indica (M), Artocarpus heterophyllus (JF), and Schizizium commune (JP)

\begin{tabular}{|c|c|c|c|c|c|c|c|}
\hline Isotherm model & Parameters & $\begin{array}{l}\text { M } \\
\text { (present study) }\end{array}$ & $\begin{array}{l}\text { JF } \\
\text { (present study) }\end{array}$ & $\begin{array}{l}\text { JP } \\
\text { (present study) }\end{array}$ & $\begin{array}{l}\text { Starch maghemite } \\
\text { (Siddiqui et al. } \\
\text { 2020) }\end{array}$ & Date seed [10] & $\begin{array}{l}\text { Delonix seed } \\
\text { biochar (Pal al. } \\
\text { 2021) }\end{array}$ \\
\hline \multirow[t]{3}{*}{ Langmuir model } & $b_{o}(\mathrm{~L} / \mathrm{mg})$ & 0.165 & 0.094 & 0.195 & 17.5 & 2.93 & 2.93 \\
\hline & $q_{m}(\mathrm{mg} / \mathrm{g})$ & 15.29 & 54.6 & 21.74 & 7.15 & 3.2 & 6.2 \\
\hline & $R^{2}$ & 0.248 & 0.041 & 0.205 & 0.98 & 0.95 & 0.92 \\
\hline \multirow[t]{3}{*}{ Freundlich model } & $K_{f}(\mathrm{mg} / \mathrm{g})$ & 0.365 & 29.25 & 0.360 & 13.8 & 22.43 & 11.09 \\
\hline & $1 / n$ & 1.044 & 2.11 & 1.059 & 0.512 & 1.23 & 1.07 \\
\hline & $R^{2}$ & 0.99 & 0.992 & 0.984 & 0.93 & 0.90 & 0.907 \\
\hline \multirow[t]{3}{*}{ Temkin model } & $b_{T}\left(\mathrm{~J} \mathrm{~mol}^{-1}\right)$ & 258.37 & 214.95 & 258.66 & 0.94 & 1.32 & 1.22 \\
\hline & $K_{T}\left(\mathrm{~L} \mathrm{~g} \mathrm{~g}^{-1}\right)$ & 0.0256 & 0.0338 & 0.0247 & 1.23 & 30.08 & 24.25 \\
\hline & $R^{2}$ & 0.966 & 0.992 & 0.94 & 0.94 & 0.91 & 0.953 \\
\hline
\end{tabular}

of arsenic metal) and dependent variable (\% removal), as shown in Eq. (2). The variation of percentage arsenic removal with adsorbent dose, $\mathrm{pH}$, and initial concentration using seed biomass catalyst of $\mathrm{M}$, JF, and JP is shown in Fig. 5.

The percentage arsenic removal has been calculated after each experimental run, response has been provided to the Design of Expert software for statistical analysis, and quadratic model was obtained which relates the independent variables with dependent variable for a mango seed catalyst as shown in below model in Eq. (3).
For JP catalyst, the model (d) was developed which is significant as it shows a very high value of model $F$-value (82.20). The DOE predicts the value of \% removal for each run after analysis which is plotted verses actual experimental data and shown in Fig. 5 III (c), which shows a correct match with the value of $R^{2}$ is 0.99 between these data; hence, model is called significant.

The variation of removal percentage of arsenic by using different biochar was shown in Fig. 5 (I, II, III). Effects of interaction time (0-120 min) on the adsorption of arsenic by the M, JF and bio-adsorption are showed in Fig. 6 .

$$
\begin{gathered}
\text { \%removal }=+59.79-9.53 p H+0.592 C D+25.52 C+0.97 p H^{2} \\
-0.0019 C D^{2}-4.025 C^{2}+0.0015 p H * C D-0.15 p H * C-0.171 * C D * C
\end{gathered}
$$

In Fig. 5 I (c), the curve fitting between predicted verses actual is shown. Similarly, all experiments have been performed with JF catalyst and model (4) found as shown below:
The sorption percentage also increases and shows a linear behavior in between 15 and $80 \mathrm{~min}$. The sorption quickly takes place and is generally measured by the amount of

\%removal $=+69.07563-2.12625 p H-0.21887 C D+13.015 C+0.43313 p H^{2}$

$+0.0015 C D^{2}-2.03 C^{2}+0.021 p H * C D-0.675 p H * C-0.0325 * C D * C$

$\mathrm{JF}$ catalyst is used to develop this model which shows the extent of dependency of dependent variable (\% removal) on self-governing parameters. The model $F$-value indicates a significant model with high value of 73.74. Another indicative of significant model is the value of $R^{2}$ which is found to be 0.99 . After analysis, the DOE predicts the value of $\%$ removal for each run which is plotted versus the actual experimental data, and shown in Fig. 5 II (c) which shows a clear match between these data; hence, the model is called significant.

Experiments have been performed with JP catalyst in similar manner and found the model (5) as shown below: heavy metal diffuses on the catalyst surface from bulk. As on reaction proceeds for long time, active sites are being drenched with more arsenic ions.

The alteration of $\mathrm{pH}$ of the solution has effect on adsorption process, which alters the active site ionization of useful functional group [23]. Figure 7 shows the adsorption capacity of all three catalysts by alteration of $\mathrm{pH}$ value within the range mentioned and found that the percentage removal is strongly depending on $\mathrm{pH}$ value. It was observed that the arsenic removal increases by increasing the $\mathrm{pH}$ value to 8.4 from 5 and then it declines for higher value. Figure

\%removal $=+60.042-5.587 p H+0.031 C D+21.85 C+0.564 p H^{2}$

$-0.0014 C D^{2}-3.775 C^{2}+0.018 p H * C D-0.262 p H * C-0.0112 * C D * C$ 

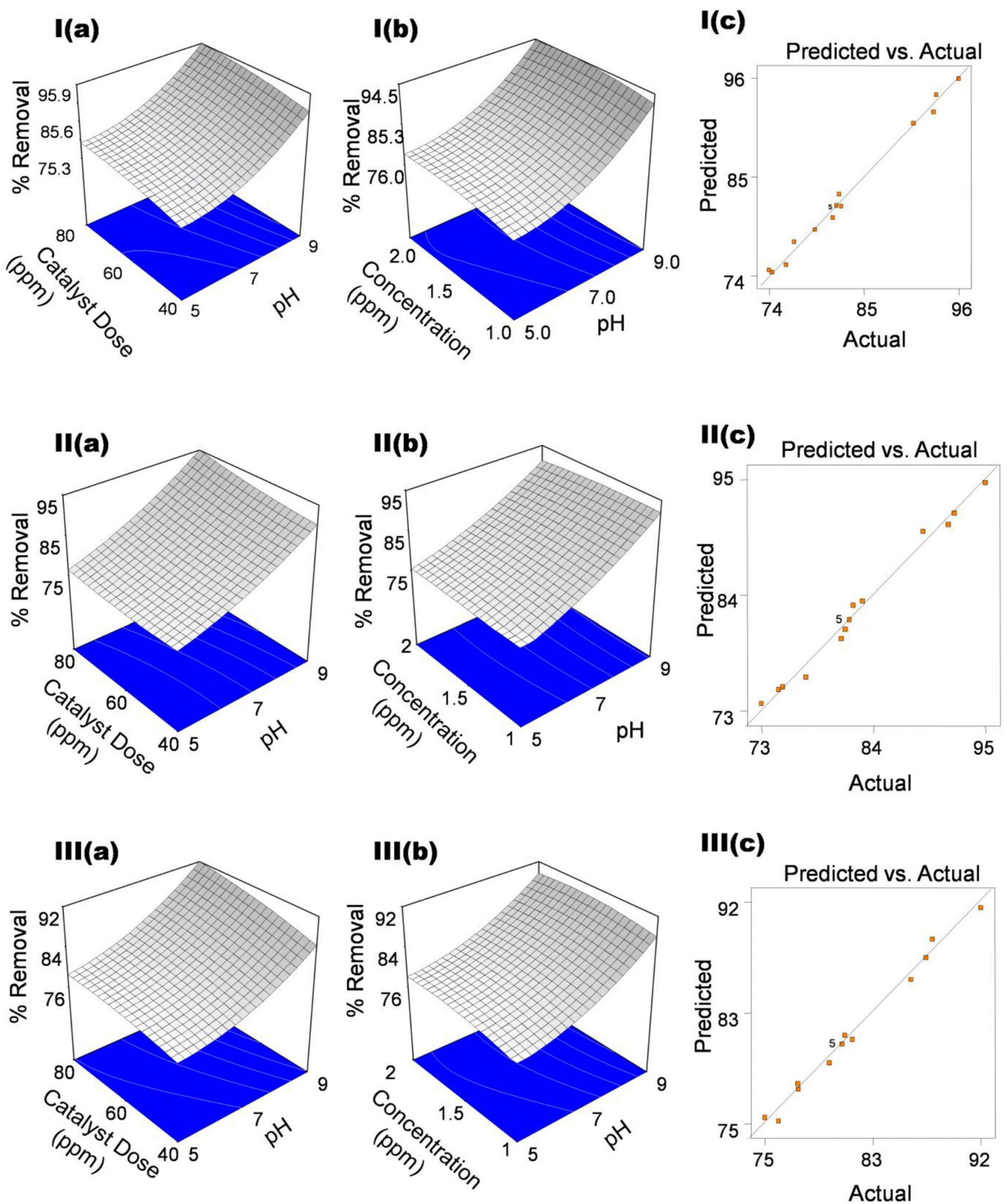

Fig. 5 Shown the arsenic removal with adsorbent dose, $\mathrm{pH}$ and concentaration of aatalyst (I, (a), (c), (b)) MF-bioadsorbent, (II, (a), (c), (b)) JFbioadsorbent and (III, (a), (c), (b)) JP-bioadsorbent 
Fig. 6 Comparative detail of reaction order of arsenic sorption by seed bio-sorbent of Mangifera indica (MF), Artocarpus heterophyllus (JF), and Schizizium commune (JP)
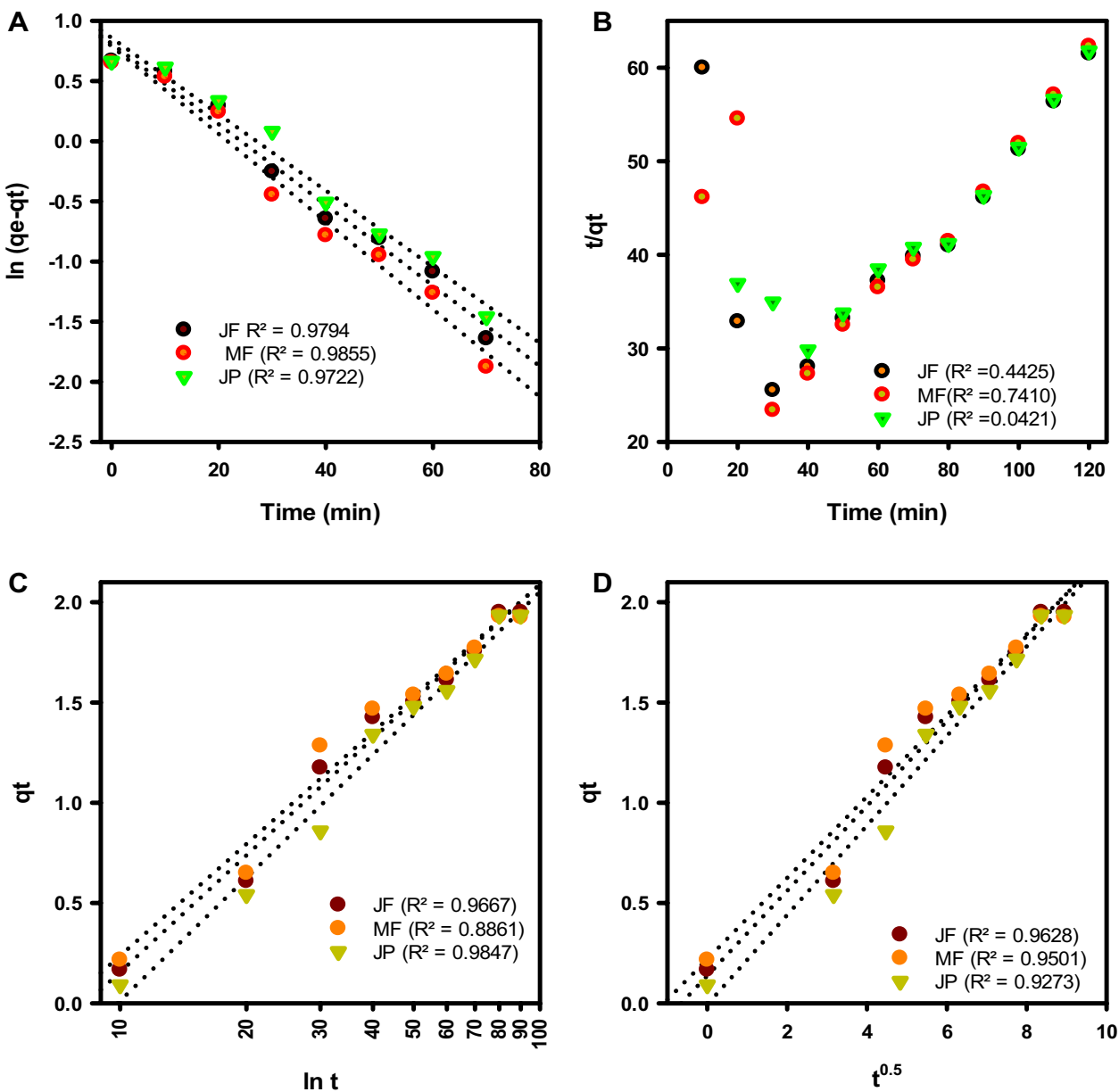

shows the maximum percentage removal was observed at $\mathrm{pH}$ value of 8.4. Figure 5 showed the removal efficiency continuously enhancing as raising the $\mathrm{pH}$ up to 8.4. Therefore, all the experiments were further performed at $\mathrm{pH} 8.4$.

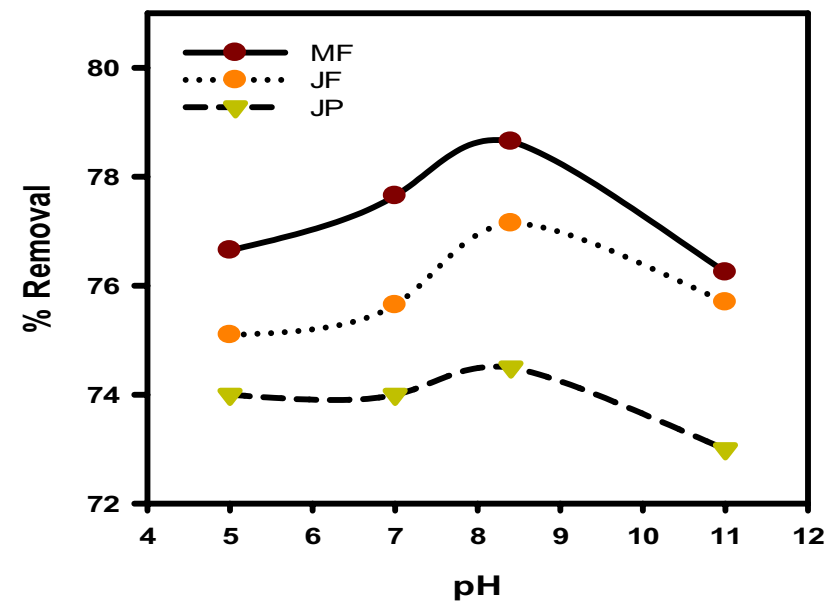

Fig. 7 Influence of solution $\mathrm{pH}$ on arsenic \% removal (contact time $=90 \mathrm{~min}, \mathrm{pH}=8.4$, initial concentration $=2.5 \mathrm{mg} . \mathrm{L}^{-1}$, agitation speed $=400 \mathrm{rpm}$, room temperature)
This adsorption behavior of arsenic at various pHs also be the survival of arsenic in various oxyanions appearance. A similar study was done by Issa and coauthors concluded that

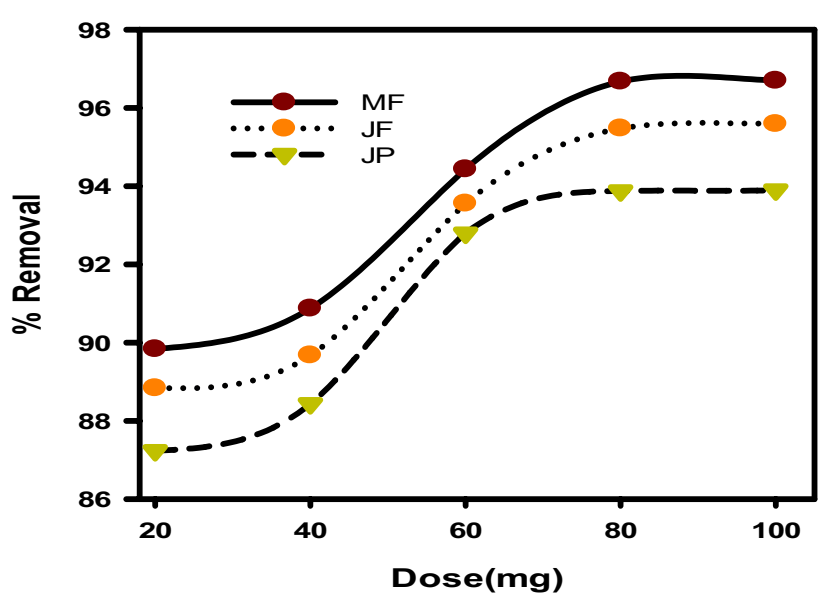

Fig. 8 Influence of seeds bio-sorbent dosage on arsenic \% removal (contact time $=90 \mathrm{~min}, \mathrm{pH}=8.4$, initial concentration $=2.5 \mathrm{mg} . \mathrm{L}^{-1}$, agitation speed $=400 \mathrm{rpm}$, room temperature) 

ent dose of Mangifera indica (MF), Schizizium commune (JP), and Artocarpus heterophyllus (JF) on the equilibrium concentration at various initial concentrations $\left(C_{0}\right)$ at $\mathrm{pH} 8.4$
Fig. 9 Effect of seed bio-sorb-
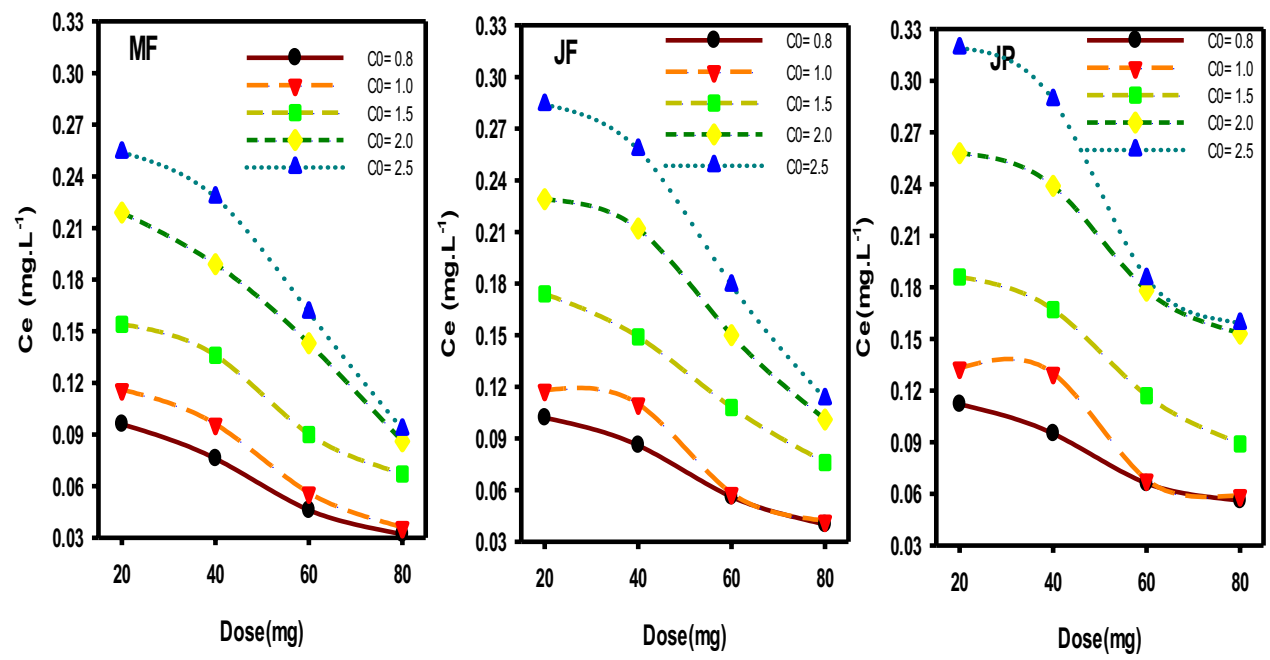

Table 4 Comparative study of arsenic removal with other parameters

\begin{tabular}{llllll}
\hline Bio-adsorbents & $\begin{array}{l}\text { Adsorption } \\
\text { capacity }(\mathrm{mg} / \mathrm{g})\end{array}$ & $\mathrm{pH}$ & $\begin{array}{l}\text { Adsorption } \\
\text { time (hrs) }\end{array}$ & \% Removal & Reference \\
\hline Date seed biochar & 6.2 & $3-8$ & 2 & 95 & Pal et al. [10] \\
Delonix seed biochar & 3.2 & $3-8$ & 2 & 93.8 & Pal et al. [10] \\
Pine wood char & 2.6 & $2-10$ & 5 & 79 & Mohan et al. [15] \\
Moringastenopetala & 1.28 & $2-9$ & 8 & 87 & Aregawi et al. [31] \\
Amaltash seed & 1.42 & $3-9$ & 1.5 & 91 & Giri et al. [9] \\
Mango seeds (MF) & 1.926 & $3-12$ & 2 & 94 & Current study \\
Jackfruit seeds (JF) & 1.487 & $3-12$ & 1.5 & 93 & Current study \\
Jamun seeds (JP) & 1.934 & $3-12$ & 1.5 & 92 & Current study \\
\hline
\end{tabular}

the $\mathrm{pH}$ of synthetic wastewater is very useful parameters for adsorption.

The effect of various doses on the adsorption of arsenic by the composite is presented in Figs. 5, 8, and 9. The highest arsenic removal M (94\%), JF (93\%), and JP (92\%) was recorded by $60 \mathrm{mg}$ any other changes there was no effect on percentage adsorption. The chitosan-magnetic graphene oxide showed a high adsorption capacity (90.91 mg/g) at favorable neutral $\mathrm{pH}$ and superior removal efficiencies as high as $89 \%$ within 50 min [24]. Xu and co-authors investigated the maximum adsorption capacity arsenic was around $7.72 \mathrm{mg} \mathrm{g}^{-1}$ by using iron-based economical and eco-friendly biochar [25].

Study shows better removal in less adsorption time and other comparative study on the effect of various parameters has been presented in Table 4. Numerous researchers have presented similar work with different bio-adsorbent and results are well matched with literature, date seed [10], delonix seed biochar [10], wood char [26], moringa stenopetala [31], almond shell [33], and amaltash seed biochar [9].

\section{Conclusion}

Synthesized bio-sorbents from the seeds of mango, jack fruit, and java plum well suited for the arsenic removal from the simulated wastewater. Seeds bio-adsorbent of Mangifera indica, Artocarpus heterophyllus, and Schizizium commune removed $94 \%, 93 \%$, and $92 \%$ respectively within one and half hour duration of batch experiment at $\mathrm{pH} 8.4$ and room temperature. The arsenic (As III) adsorption behavior of the seed's biochar was well fitted in terms of Freundlich isotherm, with the optimum adsorption capacity $0.365,29.25$, and $0.360 \mathrm{mg} \mathrm{g}^{-1}$ in $90 \mathrm{~min}$ for MF, JF, and JP, correspondingly, whereas pseudo-second order and Elovich model were able to explain the kinetic data.

Supplementary Information The online version contains supplementary material available at https://doi.org/10.1007/s13399-021-02078-5.

Acknowledgements The authors thankfully acknowledge Birla Institute of technology, Mesra, Ranchi, Jharkhand and IIT (BHU), Varanasi for characterization of the materials. DBP is thankful to NPIU (TEQIP-III), Govt. of India for the financial support The authors would 
like to extend their sincere appreciation to Taif UniversityResearchers Supporting Project Number (TURSP-2020/208), Taif University, Saudi Arabia.

\section{Declarations}

Conflict of interest The authors declare no competing interests.

\section{References}

1. WHO (2010) Exposure to arsenic: a major public health concern. Agriculture 2010:5. https://doi.org/10.1016/j.ecoenv.2011.12.007

2. Podgorski J, Berg M (2020) Global threat of arsenic in groundwater. Science 368(6493):845-850

3. Goessens T, De Baere S, Deknock A, De Troyer N, Van Leeuwenberg R, Martel A, ... \& Croubels S (2022) Agricultural contaminants in amphibian breeding ponds: Occurrence, risk and correlation with agricultural land use. Science of the Total Environment, 806, 150661.

4. Ndakidemi PA, Hutchinson TH (2021) Assessment of arsenic status and distribution in Usangu agro-ecosystem-Tanzania. J Environ Manag 294:113012

5. Kumar PS, Ramalingam S, Senthamarai C, Niranjanaa M, Vijayalakshmi P, Sivanesan S (2010) Adsorptionof dye from aqueous solution by cashew nut shell: studies on equilibrium isotherm, kinetics and thermodynamics of interactions. Desalination 261:52-60

6. Zakhar R, Derco J, Cacho F (2018) An overview of main arsenic removal technologies. Acta Chimica Slovaca 11(2):107-113

7. Rasheed H, Slack R, P. (2016) Kay Human health risk assessment for arsenic: a critical review. Environ Sci Technol 46:1529-1583

8. Pal DB, Giri DD, Singh P, Pal S, Mishra PK (2017) Arsenic removal from synthetic waste water by $\mathrm{CuO}$ nano-flakes synthesized by aqueous precipitation method. Desalin Water Treat 2017(62):355-359

9. Giri DD, Jha J, Tiwari AK, Srivastava N, Hashem A, Alqarawi AA, Elsayed F, Pal DB (2021) Java plum and amaltash seed biomass based bio-adsorbents for synthetic wastewater treatment. Environ Pollut 280:116890

10. Pal DB, Singh A, Jha J, Srivastava N, Hashem A, Alakeel MA, Abd-Allah EF, Gupta VK (2021) Low-cost biochar adsorbents prepared from date and delonix regia seeds for heavy metal sorption. Bioresour Technol 339:125606

11. Pal DB, Lavania R, Srivastava P, Singh P, Madhav S, Mishra PK (2018) Photo-catalytic degradation of methyl tertiary butyl ether from wastewater using $\mathrm{CuO} / \mathrm{CeO} 2$ composite nanofiber catalyst. J Env Chem Engg 6:2577-2587

12. Rastogi A, Tiwari MK, Ghangrekar MM (2021) A review on environmental occurrence, toxicity and microbial degradation of non-steroidal anti-inflammatory drugs (NSAIDs). J Environ Manag 300:113694

13. Shahriar A, Tan J, Sharma P, Hanigan D, Verburg P, Pagilla K, Yang Y (2021) Modeling the fate and human health impacts of pharmaceuticals and personal care products in reclaimed wastewater irrigation for agriculture. Environ Pollut 276:116532

14. Prasad N, Thakur P, Pal DB (2020) Cadmium removal from aqueous solution by jackfruit seed bio-adsorbent. Springer Nature Applied Sciences 2:1018

15. Mondal MKR (2017) Garg A comprehensive review on removal of arsenic using activated carbon prepared from easily available waste materials. Environ Sci Pollut Res 1-12

16. Farhan AM, Salem NM, Al-Dujaili AH, Awwad AM (2012) Biosorption of $\mathrm{Cr}(\mathrm{VI})$ Ions from electroplating wastewater by walnut shell powder. Am J Environ Eng 2(6):188-195

17. Issa NB, Ognjanović VNR, Jovanović BM, Rajaković LV (2010) Determination of inorganic arsenic species in natural waters-Benefits of separation and preconcentration on ion exchange and hybrid resins. Anal Chim Acta 673:185-193

18. Joshi S (2019) ManobinSharma, AnshuKumari, Surendra Shrestha and Bhanu Shrestha, Arsenic Removal from water by adsorption onto iron oxide/nano-porous carbon magnetic composite. Appl Sci 9:3732

19. Zhang H, Omer AM, Hu Z, Yang L, Ji C, Ouyang X (2019) Fabrication of magnetic bentonite/carboxymethyl chitosan/sodium alginate hydrogel beads for $\mathrm{Cu}$ (II) adsorption. Int J Biol Macromol 135:490-500

20. Siddiqui SI, Singhb PN, Tara N, Pal S, Chaudhry SA, Sinha I (2020) Arsenic removal from water by starch functionalized maghemitenano-adsorbents: thermodynamics and kinetics investigations. Colloid Interface Sci Commun 36:100263

21. Kan CC, Ibe AH, Rivera KKP, Arazo RO, de Luna MDG (2017) Hexavalent chromium removal from aqueous solution by adsorbents synthesized from ground water treatment residuals. Sustain Environ Res 27:163-171

22. Idrees M, Batool S, Ullah H, Hussain Q, Mohammad M, Ahmad A, Hussain M, Riaz Y. Sik (2018) Jie Kong Adsorption and thermodynamic mechanisms of manganese removal from aqueous media by biowaste-derived biochars. J Mol Liq 266:373-380

23. Aggarwal S, Singh NB (2016) Removal of arsenic from aqueous solution by an adsorbent nickel ferrite-polyaniline nanocomposite. Indian J Chem Technol 5:374-383

24. Gabris MA, Rezania S, Rafieizonooz M, Khankhaje E, Devanesan S, AlSalhi MS, Shadravan A (2021) Chitosan magnetic graphene grafted polyaniline doped with cobalt oxide for removal of arsenic (V) from water. Environ Res 112209

25. Xu Z, Wan Z, Sun Y, Cao X, Hou D, Alessi DS, ..., Tsang DC (2021) Unraveling iron speciation on Fe-biochar with distinct arsenic removal mechanisms and depth distributions of As and Fe. Chem Eng J 425, 131489

26. Mohan D, Pittman CU (2007) Arsenic removal from water/wastewater using adsorbents-a critical review. J Hazard Mater 142:1-53

27. Hashemi F, Olesen JE, Jabloun M, \& Hansen A (2018) Reducing uncertainty of estimated nitrogen load reductions to aquatic systems through spatially targeting agricultural mitigation measures using groundwater nitrogen reduction. Journal of environmental management, 218, 451-464.

28. Gaurav N, Sivasankari S, Kiran GS, Ninawe A, \& Selvin J (2017) Utilization of bioresources for sustainable biofuels: a review. Renewable and Sustainable Energy Reviews, 73, 205-214.

29. Liew RK, Azwar E, Yek PNY, Lim XY, Cheng CK, Ng JH, ... \& Lam SS (2018) Microwave pyrolysis with $\mathrm{KOH} / \mathrm{NaOH}$ mixture activation: a new approach to produce micro-mesoporous activated carbon for textile dye adsorption. Bioresource technology, 266, 1-10.

30. Kian LK, Jawaid M, Ariffin H, Karim Z 2018 Isolation and characterization of nanocrystalline cellulose from roselle-derived microcrystalline cellulose, Int. J. Biol. Macromol. 114, 54-63,

31. Aregawi BH, Mengistie AA 2013 Removal of Ni (II) from aqueous solution using leaf, bark and seed of Moringa stenopetala adsorbents, Bull. Chem. Soc. Ethiop. 7, 35-47.

32. Theivasanthi TG, Venkadamanickam M, Palanivelu M, Alagar 2011 Nano sized Powder of Jackfruit Seed: Spectroscopic and Anti-microbial Investigative Approach. Nano Biomed. Eng. 3(4):215-221.

33. Pehlivan E, Altun T 2008 Biosorption of chromium (VI) ion from aqueous solution using walnut, hazelnut and almond shell, J. Hazard. Mater. 155 (1-2):378-384.

34. Abdel-Ghani N, Hegazy AK, El-Chaghaby G, 2009 Typha domingensis leaf powder for decontamination of aluminium, iron, zinc and lead: Biosorption kinetics and equilibrium modelling international journal of Environmental Science and Technology 6(2) https://doi.org/10.1007/BF03327628

Publisher's note Springer Nature remains neutral with regard to jurisdictional claims in published maps and institutional affiliations. 